\title{
Measurement of stable carbon and oxygen isotope ratios of individual otoliths of early developmental stage Japanese anchovy and sardine with the MICAL3c microscale stable isotope analytical system
}

\author{
K. NISHIDA ${ }^{1,2 *}$, A. YASU ${ }^{1,3}$, N. NANJO ${ }^{4,5}$, \\ M. TAKAHASHI ${ }^{6}$, S. KITAJIMA ${ }^{6}$ AND T. ISHIMURA ${ }^{1}$
}

${ }^{1}$ National Institute of Technology, Ibaraki Coll., Hitachinaka, Japan (*correspondence: koz.nishida@gmail.com)

2 JSPS, Tokyo, Japan

${ }^{3}$ The University of Tsukuba, Japan

${ }^{4}$ Himi Sea Farming Center, Toyama Pref. Agriculture, Forestry \& Fisheries Research Center, Himi, Japan

${ }^{5}$ Toyama Prefectural Agricultural, Forestry \& Fisheries Research Center, Namerikawa, Japan

${ }^{6}$ Seikai National Fisheries Research Institute, Japan Fisheries Research \& Education Agency, Nagasaki, Japan

The stable isotopes of fish otoliths are natural tags that can be an useful alternative to artificial tags for inferring the environmental history of fish. To expand the potential use of otoliths from small fish for carbon and oxygen isotope $\left(\delta^{13} \mathrm{C}\right.$, $\left.\delta^{18} \mathrm{O}\right)$ analysis, we analyzed individual otoliths from larval and juvenile Sardinops melanostictus and Engraulis japonicus collected from Toyama Bay by a submicrogramscale stable isotopic analytical system called MICAL3c.

Both otolith $\delta^{13} \mathrm{C}$ and $\delta^{18} \mathrm{O}$ of two species showed decreasing trends with growth. Otolith $\delta^{18} \mathrm{O}$ values may record a decline in salinity (seawater $\delta^{18} \mathrm{O}$ ) rather than seasonal increase in temperature during the transportation from the spawning to the fishing grounds, or a change in the $\mathrm{pH}$ of the calcification fluid with growth. From the observed environmental data, sea surface salinity in Toyama Bay was drastically declined along the southern shore compared with elsewhere in the bay, whereas the sea surface temperature distribution was rather uniform. Considering the observed environmental data and the eggs and larvae abundance distributions in the bay, we inferred that horizontal transport, such as by the counterclockwise eddy that forms in Toyama Bay in summertime, is more likely to be recorded in the otolith $\delta^{18} \mathrm{O}$. In addition, otolith $\delta^{13} \mathrm{C}$ values might be affected by physiological changes (e.g., in metabolism and calcification physiology) during the early life stage, or changes in seawater $\delta^{13} \mathrm{C}$. Thus, knowledge of otolith $\delta^{13} \mathrm{C}$ and $\delta^{18} \mathrm{O}$ has the potential to deepen our understanding of the ecology of fishes in their early developmental stages. 